\title{
Early effects of roflumilast on insulin sensitivity in adults with prediabetes and overweight/obesity involve age-associated fat mass loss - results of an exploratory study
}

This article was published in the following Dove Medical Press journal:

Diabetes, Metabolic Syndrome and Obesity:Targets and Therapy

ljeoma M Muo,' Sandra D MacDonald, ${ }^{2}$ Ritu Madan, ${ }^{3}$ SungJun Park,' Ahmed M Gharib, ${ }^{4}$ Pedro E. Martinez, ${ }^{5}$ Mary $F$ Walter, ${ }^{3}$ Shanna B Yang, ${ }^{6}$ Justin A Rodante, ${ }^{7}$ Amber B Courville, ${ }^{6}$ Peter J Walter, ${ }^{8}$ Hongyi Cai, ${ }^{8}$ Michael Glicksman, ${ }^{3}$ Gioia M Guerrieri, ${ }^{5}$ Rivka R Ben-Dor, ${ }^{9}$ Ronald Ouwerkerk, ${ }^{4}$ Stephanie Mao,' Jay H Chung'

'Laboratory of Obesity and Aging Research NHLBI, National Institutes of Health, Bethesda, MD 20892, USA; ${ }^{2}$ NHLBI Pulmonary Branch, Laboratory of Chronic Airway Infections, National Institutes of Health, Bethesda, MD 20892, USA; ${ }^{3}$ Diabetes Endocrinology and Obesity Branch, NIDDK, National Institutes of Health, Bethesda, MD 20892, USA; ${ }^{4}$ Biomedical and Metabolic Imaging Branch NIDDK, National Institutes of Health, Bethesda, MD 20892, USA; ${ }^{5}$ Section on Behavioral Endocrinology, NIMH, National Institutes of Health, Bethesda, MD 20892, USA; ${ }^{6}$ Clinical Center Nutrition Department, National Institutes of Health, Bethesda, MD 20892, USA; 'Laboratory of Inflammation and Cardiometabolic Diseases, NHLBI, National Institutes of Health, Bethesda, MD 20892, USA; ${ }^{8}$ Mass Spectrometry Clinical Core, NIDDK, National Institutes of Health, Bethesda, MD 20892, USA; ' $\mathrm{NIMH,} \mathrm{National} \mathrm{Institutes} \mathrm{of}$ Health, Bethesda, MD 20892, USA

Correspondence: Jay $\mathrm{H}$ Chung

Laboratory of Obesity and Aging Research NHLBI, National Institutes of Health, BIdg 10-7D I4, 10 Center Drive, Bethesda, MD 20892, USA

$\mathrm{Tel}+\mathrm{I} 3014963075$

Fax +13014518369

Email chungj@nhlbi.nih.gov

ljeoma M Muo

Laboratory of Obesity and Aging Research NHLBI, National Institutes of Health, BIdg 10-7DI4, 10 Center Drive, Bethesda, MD 20892, USA

Fax + I 30| 45I 8369

Email ijeoma.muo@nih.gov
Purpose: Roflumilast (Daliresp, Daxas) is a FDA-approved phosphodiesterase 4 (PDE4) inhibitor for the treatment of moderate-to-severe chronic obstructive pulmonary disease. In mice and in limited human studies, this oral medication can cause weight loss and improve insulin sensitivity. We set out to determine the mechanism of its effect on insulin sensitivity.

Patients and methods: Eight adults with overweight/obesity and prediabetes received roflumilast for 6 weeks. Before and after roflumilast, subjects underwent tests of insulin sensitivity, mixed meal test, body composition, markers of inflammation, and mitochondria function. Dietary intake and physical activity were also assessed. Our primary outcome was the change in peripheral insulin sensitivity, as assessed by the hyper-insulinemic euglycemic clamp.

Results: This study was underpowered for the primary outcome. Pre- and post-roflumilast mean peripheral insulin sensitivity were 48.7 and $70.0 \mathrm{mg} / \mathrm{g}$ fat free mass/minute, respectively, $(P$-value $=0.18)$, respectively. Among the mixed meal variables, roflumilast altered glucagonlike peptide 1 (GLP-1) hormone the most, although the average effect was not statistically significant $(P=0.18)$. Roflumilast induced a trend toward significance in 1) decreased energy intake (from $11,095 \mathrm{KJ}$ to $8,4555 \mathrm{KJ}, P=0.07$ ), 2) decreased fat mass (from 34.53 to $32.97 \mathrm{~kg}$, $P=0.06), 3$ ) decreased total and LDL cholesterol ( $P=0.06$ for both variables), and 4 ) increased plasma free fatty acids (from 0.40 to $0.50 \mathrm{mEq} / \mathrm{L}, P=0.09$ ) The interval changes in adiposity and free fatty acid were significantly associated with the subject's age ( $P$-value range= $<0.001$ to 0.02 for the correlations). Inflammatory and adhesion markers, though unchanged, significantly correlated with one another and with incretin hormones only after roflumilast.

Conclusion: We demonstrate, for the first time in humans, increasing percentage of fat mass loss from roflumilast with increasing age in adults with prediabetes and overweight/obesity. We also demonstrate novel associations among roflumilast-induced changes in incretin hormones, inflammatory markers, peripheral insulin sensitivity, and adiposity. We conclude that roflumilast's early effects on insulin sensitivity is indirect and likely mediated through roflumilast's prioritization of lipid over glucose handling.

Clinical trials registration: NCT01862029.

Keywords: phosphodiesterase 4, obesity, diabetes, inflammation, incretins, aging

\section{Plain language summary of the research}

Roflumilast is an anti-inflammatory medication that is presently used to treat chronic obstructive pulmonary disease (COPD). Roflumilast has been shown to improve diabetes in limited clinical studies. Roflumilast inhibits an enzyme in the cell called phosphodiesterase 4 (PDE4). The PDE4 
enzyme is present in many bodily systems and is involved in oxidative stress and in inflammation. Like COPD, the dysfunction in obesity also involves oxidative stress and inflammation at its cellular level. We, therefore, conducted a study in individuals with prediabetes and overweight/obesity to further understand how roflumilast works on their metabolism. A major challenge and limitation of the study was sufficient recruitment of subjects to meet the primary goal, which was to demonstrate that roflumilast improved how well the body handled glucose (insulin sensitivity). Despite this limitation, we gained some insights into possible ways that roflumilast affected insulin sensitivity. Future studies on roflumilast are needed as roflumilast may have multiple therapeutic benefits. Investigating a drug like roflumilast with previously known long-term side-effect profiles, for use in the treatment of prediabetes, diabetes and overweight/obesity, may help to accelerate the bench to bedside path to finding solutions to non-surgical treatment of obesity and its co-morbpid conditions.

\section{Introduction}

In recent years, glucagon-like peptide 1 (GLP-1) agonists have rapidly shown greater pleiotropic benefits than most insulin analogs for the treatment of type 2 diabetes mellitus in the setting of obesity and elevated cardiovascular event risks. ${ }^{1,2}$ Such growing evidence for the superiority of GLP-1 agonists over most insulin analogs demonstrates the benefits of maximally utilizing the body's own physiological process to begin to redirect the trajectory of a pathophysiological process. This approach to treating interconnected metabolic diseases requires an in-depth understanding of factors that trigger deleterious chemical reactions on a cellular level. In obesity, harmful chemical reactions occur when lipid supply exceeds the cells' oxidative capacity and leads to the production of reactive oxygen species (ROS). These ROS destabilize the body from a cellular level as they trigger the sentinel events of inflammation and insulin resistance ${ }^{3,4}$ and generate a vicious cycle that ends in tissue remodeling, progressive metabolic decline, and increased risk of death and disability with aging. ${ }^{5,6}$ To break such a cycle, therefore, targeting sentinel-related events is critical and is likely to result in pleiotropic benefits.

One approach to address sentinel perturbations in obesity pathophysiology is by activating the enzyme, AMP-activated Protein Kinase (AMPK), through upregulation of the signaling molecule, cyclic AMP (cAMP). ${ }^{7}$ In the adipose tissue, increased AMPK facilitates an anti-inflammatory, insulin sensitive, thermogenic state ${ }^{8-10}$ In muscle, AMPK activation increases mitochondrial biogenesis and fat oxidation and improves muscle performance. ${ }^{11}$ Both physical activity and caloric restriction improve skeletal muscle insulin sensitivity through AMPK-dependent mechanisms. ${ }^{12,13}$ Furthermore, the metabolic benefits of bariatric surgery may be partly due to the post-surgical increase in AMPK levels. ${ }^{14,15}$ Among the many ways to increase AMPK is to increase cAMP levels through inhibition of the enzyme, phosphodiesterase, that degrades cyclic AMP. Presently, there are 11 known classes of phosphodiesterase. In a previous investigation by our team, we demonstrated that the anti-obesity and insulin sensitizing effects of the red wine polyphenol, resveratrol, operated through phosphodiesterase 4 (PDE4) inhibition. ${ }^{11}$ In the current clinical setting, PDE4 inhibitors are used to treat chronic inflammatory conditions such as $\mathrm{COPD}^{16}$ and psoriasis. ${ }^{17}$ The PDE4 inhibitor, roflumilast, reduces the inflammation that drives the vicious cycle of airway remodeling in patients with moderate-to-severe COPD. ${ }^{18,19}$ For this patient population, a mean weight loss of 2.2 kilograms (kg) occurred over 6-12 months of taking roflumilast. ${ }^{16}$ In contrast, in a non-COPD patient population of women with obesity and polycystic ovarian syndrome, respective weight losses of $2 \mathrm{~kg}$ and $5 \mathrm{~kg}$ from roflumilast monotherapy and roflumilast plus metformin combination therapy occurred within 3 months. ${ }^{20,21}$ Similarly, another non-COPD population of subjects with newly discovered type 2 diabetes mellitus lost an average of $1.9 \mathrm{~kg}$ and reduced their hemoglobin A1c by $0.79 \%$ after 3 months of roflumilast monotherapy. ${ }^{22}$ These research findings highlight the need to further understand roflumilast's metabolic effects in adults with overweight/ obesity and insulin resistance.

The biology of PDE4 enzyme system, however, is complex. The enzyme's detailed stratification beyond its four isoforms endows a highly controlled, but fundamental, function. ${ }^{23}$ In higher organisms, PDE4 enzyme can be found in the brain, ${ }^{24,25}$ lungs, ${ }^{24}$ immune system, ${ }^{24}$ adipose tissue, ${ }^{26,27}$ skeletal muscles, ${ }^{28}$ heart, ${ }^{25}$ liver,${ }^{24}$ pancreas, ${ }^{25,29}$ intestines, ${ }^{30}$ and kidney. ${ }^{24}$ Many of these tissues, interestingly, are involved in obesity's pathophysiology. Yet PDE4's inherent complexity may, perhaps, partly explain the currently limited human studies on the mechanistic effects of PDE4 inhibitors in obesity and insulin resistance. ${ }^{20-22}$ In this study, we addressed this knowledge gap using a multi-pronged, exploratory approach. We hypothesized that roflumilast would improve insulin sensitivity in subjects with overweight/obesity and prediabetes over 6 weeks. We chose a 6 weeks study duration to minimize roflumilast's weight loss mediated effects on insulin sensitivity. We studied only subjects with prediabetes, given diabetes' clinical heterogeneity. Our primary outcome was the change in peripheral insulin sensitivity, as measured by the hyperinsulinemic euglycemic clamp. Our secondary outcomes were changes in hepatic insulin sensitivity, postprandial 
incretin response, body composition, inflammatory markers, and mitochondrial biogenesis.

\section{Materials and methods}

Research participants (males and females between 30 and 65 years of age and in good general health) were recruited from the surrounding community through print and electronic modes of advertisements. Our inclusion criteria included body mass index (BMI) between 24.9 and 39.5 $\mathrm{kg} / \mathrm{m}^{2}$, weight stability ( $\leq 2.5 \mathrm{~kg}$ weight change) for at least 6 months prior to enrollment in the study and objective evidence of prediabetes, defined as serum fasting glucose between $100 \mathrm{mg} / \mathrm{dL}$ and $125 \mathrm{mg} / \mathrm{dL}$ or hemoglobin A1c that is within the range of $5.7 \%$ and $6.5 \%$. Due to the box warning of suicidality from roflumilast, ${ }^{31}$ we also excluded subjects with psychiatric diagnoses using the Structured Clinical Interview for DSM-IV Axis I Disorders (SCID) and the Columbia-Suicide Severity Rating Scale (C-SSRS). ${ }^{32,33}$ Details on our inclusion and exclusion criteria are available at the clinicaltrials.gov website under the clinical trials registration number NCT01862029. All potential subjects signed a written informed consent form prior to undergoing full medical and psychiatric evaluation in the clinic in order to determine their eligibility. Subjects were financially compensated by the degree of their participation in the study. This study was approved by the Institutional Review Board at the National Institutes of Health and was performed according to the Declaration of Helsinki.

Subjects underwent the same set of evaluations before and after taking roflumilast. Subjects were advised to record their home diet and physical activity level with food records and an accelerometer (Actigraph, Pensacola, FL, USA), respectively, for 3 days before their inpatient stay. Upon admission, subjects met with a dietitian for a detailed review of their reported dietary intake. The dietary composition of the recorded foods and beverages was assessed using the Nutrition Data System for Research software (NDSR, Minneapolis, MN, USA). Subjects consumed a standardized diet starting at 2 days prior to their admission and remained on this diet during their inpatient stay. These diets were standardized using the ProNutra software system (Viocare Inc, Princeton, NJ, USA) and consisted of 55\% of energy from carbohydrate, $30 \%$ from fat, and $15 \%$ from protein. These diets provided energy to meet caloric needs, as estimated using the Mifflin-St. Jeor equation, ${ }^{34}$ with a standardized physical activity factor. ${ }^{35}$

Subjects were admitted to the NIH Metabolic Clinical Research Unit for 3 days and 2 nights, where they underwent tests for hepatic and peripheral insulin sensitivity, mixed meal test, and laboratory tests for inflammatory and cellular adhesion markers, lipid profile, liver and thyroid functions, hematologic and chemistry panels. The magnetic resonance imaging/magnetic resonance spectroscopy (MRI/ MRS) imaging was either performed as an outpatient when subjects picked up their standardized diets or as an inpatient. Dual energy x-ray absorptiometry (DEXA) imaging was performed on the first day of the admission. The hyperinsulinemic euglycemic clamp test and glucose tracer test of hepatic insulin sensitivity were performed on the same morning after an overnight stay, starting around 5 AM, with a 3-hour infusion of the glucose tracer. The mixed meal test was performed after another overnight stay. All subjects were in the fasting condition at the initiation of all of these tests.

\section{Assessment of peripheral insulin sensitivity}

Data for hepatic insulin sensitivity was obtained during fasting and during the clamp. The hepatic insulin resistance index was used to evaluate fasting hepatic insulin sensitivity. This index was determined by multiplying together the measured values from fasting hepatic glucose production and fasting plasma insulin concentration. A stable isotope technique with deuterium glucose as a tracer (Pine Pharmaceuticals, Tonawanda, NY, USA) was used to determine basal endogenous glucose production. Details of this method are shown in the Supplementary materials. For the hyperinsulinemic euglycemic clamp, regular insulin (Eli Lilly, Indianapolis, IN, USA) was infused at a constant rate of 40 $\mathrm{mU} / \mathrm{m}^{2} /$ minute after 8 minutes of loading dose of insulin at twice the rate. Serum glucose level was assessed every 5-10 minutes with a YSI 2700 dual chamber glucose analyzer (YSI Inc, Yellow Springs, OH, USA). The rate of intravenous glucose infusion was adjusted to keep the serum glucose level as close to $100 \mathrm{mg} / \mathrm{dL}$ as possible. Serum insulin levels, obtained during steady state glucose level, were used to calculate the measure of peripheral insulin sensitivity $(M$ value), our primary outcome measure. ${ }^{36}$

\section{Assessment of the incretin effect, circulating and inflammatory markers, and adipocytokines}

In the fasted state, and before the mixed meal test, blood samples were drawn for the measurement of leptin, adiponectin, TNF- $\alpha$, VCAM, ICAM, E-selectin, and MCP. Between the hours of 7:30-8:30 AM, a mixed meal stimulation test was performed after an overnight fast. For the test, subjects drank Boost Plus (35\% fat, $15 \%$ protein, $50 \%$ carbohydrate) to meet 
$30 \%$ of estimated daily energy needs. Glucose, insulin, C peptide, and the incretin hormones - glucagon-like peptide 1 (GLP-1) and glucose-dependent inhibitory polypeptide (GIP) - were sequentially measured at predetermined times over 5 hours. Details on the laboratory assessment of the mixed meal variables are provided in the supplement.

\section{Assessment of body composition}

Using DXA (GE Healthcare, Madison, WI, USA), we assessed total and regional body fat and fat free mass. To quantify lipids in the abdominal area, muscle, and liver, we used MRI and MRS (Magnetom Verio, Siemens Erlangen, Germany), as previously described. ${ }^{37,38}$ Intramyocellular lipid (IMCL) and extramyocellular lipid (EMCL) content of the lower extremities were quantified from the muscle portion of these imaging results. Abdominal adiposity on MRI images was assessed at the L2-L3 and at L4-L5 lumbar regions.

\section{Drug dispensing and monitoring}

To ensure tolerability, subjects started roflumilast (Astra Zeneca, Wilmington, DE, USA) on the last day of their first inpatient stay at a dose of $250 \mathrm{mcg}$ daily. A pharmacy-directed splitting of the $500 \mathrm{mcg}$ market dose of the pills was accomplished before dispensing the prescription to the subjects. After the first dose of roflumilast, subjects were observed for 2 hours for immediate adverse reactions before they were discharged. Subjects were instructed to keep a medication diary, and to bring the diary and roflumilast medication to all clinic visits. At the end of the 2 weeks, subjects underwent clinical evaluation. Roflumilast dose was increased to and maintained at $500 \mathrm{mcg}$ daily if no major adverse effects were found on evaluation. Subjects returned to the clinic 1 week later for repeat medical evaluation. All participants were instructed to contact the research team in the event of adverse symptoms. Additional clinic visits for close monitoring was at the discretion of the study team. To ensure their continued wellbeing, subjects underwent one final clinic visit at 1 week after they stopped roflumilast.

\section{Statistical analysis}

We aimed to detect a clinically relevant change of $20 \%$ from baseline in peripheral insulin sensitivity, as assessed using the glucose clamp's M value. ${ }^{36}$ To detect this percentage difference using paired $t$-test, a minimum sample size of 12 subjects was needed to ensure $80 \%$ power. ${ }^{39}$ We aimed for a sample size of 15 subjects, in order to allow for a $20 \%$ dropout rate. Paired $t$-test was used for the analysis of normally distributed data. The Shapiro-Wilk test was used to assess for normal distribution of continuous variables. The non-parametric test - Related samples Wilcoxon-Signed Rank test - was used to test for the statistical significance of pre- and post-roflumilast data pairs that were not normally distributed. Results reported herein are mean values and standard errors, except where stated otherwise. Area under the curve (AUC) for the mixed meal test variables was calculated using the trapezoid rule. All relationships between two selected study variables were assessed with Spearman correlation. All $P$-values reported are two-sided; $P<0.05$ is considered significant. SPSS Statistics version 25 (IBM Corporation, Armonk, NY, USA) was used to perform the statistical analysis.

\section{Results}

We were unable to achieve the needed sample size of 12 subjects for our primary outcome. Twenty-four subjects were screened in the clinic for the study and, of these, 14 subjects met the inclusion criteria and enrolled in the study. However, before the subjects began roflumilast, three subjects withdrew from the study due to their anticipated inability to meet the study demands, one subject reported an emergent appendectomy and, thus, withdrew from the study. One subject was withdrawn for a concerning new incidental finding on imaging. Therefore, nine subjects started roflumilast medication. Out of these subjects, one subject (a female) was withdrawn after 2 weeks of roflumilast because of new onset of bothersome insomnia and due to an unreported baseline symptom (atypical chest pain). Therefore, eight subjects completed the study (Table S1, Supplementary materials). The study completers were six men and two women and consisted of five African or African-Americans, two Caucasians, and one Hispanic. Mean age was 48.5 years ( $\mathrm{SD}=4.2$ years). Average BMI was $31.2 \mathrm{~kg}$ / $\mathrm{m}^{2}\left(\mathrm{SD}=3.3 \mathrm{~kg} / \mathrm{m}^{2}\right)$. Mean HbA1c was $5.8 \%(\mathrm{SD}=0.13 \%)$. Six out of the eight subjects were taking either no medication or were taking only a multivitamin at baseline. Two subjects were on a statin medication. One male subject had laboratory evidence of severe insulin resistance at baseline without an unusual clinical explanation.

\section{Effect of roflumilast on peripheral insulin sensitivity}

Peripheral insulin sensitivity as measured by the glucose disposal rate, $M$ value, was, on average, unchanged for the seven subjects with complete data $(P=0.18)$ (Table 1). Mean percentage change in $\mathrm{M}$ value from its baseline was, however, $46 \%$, and six out of these seven subjects had over a $20 \%$ increase from baseline in their $M$ values. Percentage change in $\mathrm{M}$ value correlated significantly with percentage changes 
in leptin and in L4-L5 visceral fat (Figures $1 \mathrm{E}$ and F). In the six subjects with paired data, we observed no interval changes in basal hepatic glucose output or in fasting hepatic insulin sensitivity (Table 1). We were unable to assess the effect of roflumilast on insulin suppression of hepatic gluconeogenesis, as originally planned, because of the technical limitations of the laboratory analysis process. Hemoglobin A1c was 5.72\% $(\mathrm{SE}=0.09)$ after 6 weeks on roflumilast.

\section{Effects of roflumilast on the incretin hormones}

For the mixed meal test, the average energy intake of the test drink was 3,250 $\mathrm{KJ}$ ( $\mathrm{SE}=153$ ). We found no significant interval change in the AUC for $\mathrm{C}$ peptide, glucose, and the two incretin hormones assessed. Mixed meal C-peptide
AUC was analyzed in lieu of insulin AUC because several insulin samples from the mixed meal test were hemolyzed and, thus, could not be reliably used for analysis. ${ }^{40}$ Of all of the mixed meal variables assessed, roflumilast affected GLP-1 AUC the most (Table 2). The range of the percentage change in GLP-1 AUC varied from $-51 \%$ to $+476 \%$, with six out of the eight subjects having an increase in their GLP-1 AUC. Interestingly, the two subjects who had an interval decrease in their GLP-1 AUC both had an interval increase in their L4-L5 visceral fat content (Figure 1B) and over a $50 \%$ interval increase in their soleus EMCL content (Figure 1C). Roflumilast-induced changes in postprandial GLP-1 AUC also correlated significantly with percentage changes in the L4-L5 abdominal fat region (Figures 1A and B), but not in the L2-L3 abdominal fat regions.

Table I Variables determined from the hyper-insulinemic euglycemic clamp procedure

\begin{tabular}{|l|l|l|l|l|}
\hline Variable, units of measurement & $\begin{array}{l}\text { Total number } \\
\text { of subjects }\end{array}$ & $\begin{array}{l}\text { Pre-roflumilast, } \\
\text { mean (SE) }\end{array}$ & $\begin{array}{l}\text { Post-roflumilast, } \\
\text { mean (SE) }\end{array}$ & \begin{tabular}{l} 
P-value \\
\hline Fasting plasma glucose, $\mathrm{mg} / \mathrm{dL}$
\end{tabular} \\
\hline Fasting plasma insulin, $\mathrm{mcU} / \mathrm{mL}$ & 6 & $100.7(3.4)$ & $100.5(2.7)$ & $0.94^{*}$ \\
\hline Basal hepatic glucose production, $\mathrm{mg} / \mathrm{kg}$ lean mass/minute & 7 & $20.6(7.9)$ & $27.3(13.4)$ & $0.46^{*}$ \\
\hline Hepatic insulin resistance index & 6 & $2.45(0.13)$ & $2.78(0.22)$ & 0.10 \\
\hline Mean M value, $\mathrm{mg} / \mathrm{g}$ fat free mass/minute & 7 & $47.7(15.7)$ & $68.4(27.7)$ & $0.35^{*}$ \\
\hline
\end{tabular}

Notes: *P-value as determined using Related Samples-Wilcoxon Signed Rank Test. All other $P$-values are from paired $t$-test analysis.

A

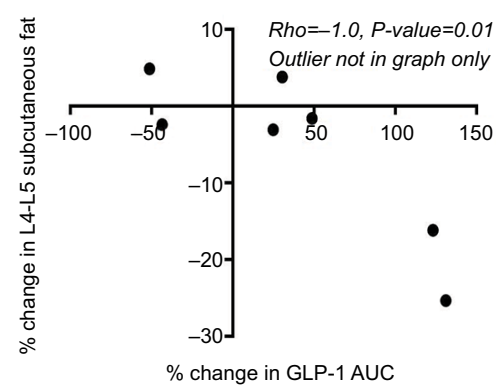

D

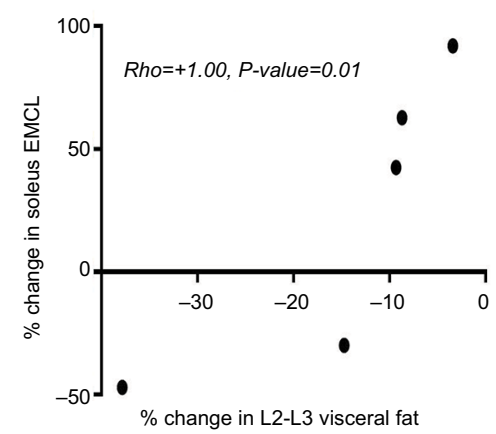

B

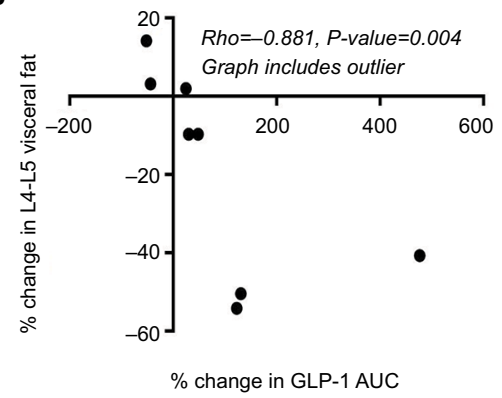

E

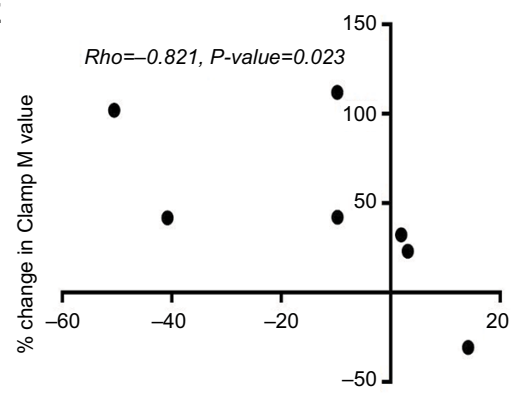

$\%$ change in L4-L5 visceral fat
C

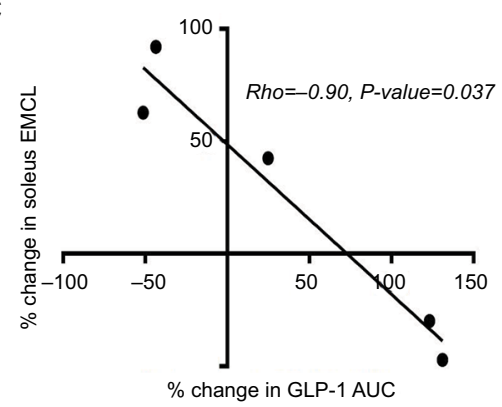

$\mathbf{F}$

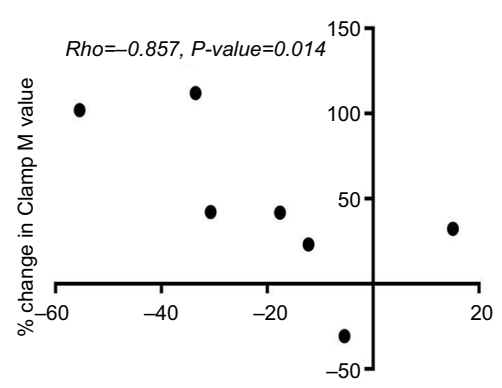

$\%$ change in leptin

Figure I Spearman correlation demonstrating the significant associations among percentage changes in GLP-I hormone and visceral adiposity in the leg skeletal muscle and in the abdomen, peripheral insulin sensitivity and leptin $(\mathbf{A}-\mathbf{F})$. Roflumilast induced alteration of insulin sensitivity is associated with changes in leptin (F) and in visceral adiposity (E).

Notes: In this small study, the association of changes in GLP-I AUC with changes in adiposity (A-C) suggests that roflumilast's early effects on insulin sensitivity may be through reduction in adiposity and/or through incretin effect. Roflumilast-induced association between changes in soleus EMCL and L2-L3 visceral fat (D) highlights possible linkage between these two anatomically separate, visceral fat depot.

Abbreviations: AUC, area under the curve; EMCL, extramyocellular lipid; GLP, glucagon-like peptide. 


\section{Effect of roflumilast on body weight and body composition}

The mean total body weight before and after roflumilast were $97.98 \mathrm{~kg}(\mathrm{SE}=4.8)$ and $96.26 \mathrm{~kg}(\mathrm{SE}=5.2)$, respectively. One subject lost $7.5 \%$ of his body weight during the study without any reported change in his appetite. No other subjects experienced this degree of weight loss. Average body weight change was $-1.71 \mathrm{~kg}(P=0.12)$ and was due to fat mass loss $(P=0.06)$, most significantly in the $\mathrm{L} 2-\mathrm{L} 3$ visceral region $(P=0.03)$ (Tables $3 \mathrm{~A}$ and $\mathrm{B})$. No significant changes in the abdominal subcutaneous or liver fat content were observed. We observed very significant correlations involving age and percentage changes in: 1) plasma free fatty acid, 2) leg fat, 3) total body fat, and 4) trunk fat (Figures $2 A-D$ ).
Due to the technicality of the MRI procedure, complete MRI data of the lower extremities was obtainable in five of the eight subjects (Table 3C). On average, roflumilast decreased subjects' IMCL and increased their extramyocellular lipid content - EMCL (Table 4). The percentage change in soleus EMCL significantly correlated with percentage changes in the L2-L3 visceral fat content and GLP-1 AUC (Figures 1C and D), but showed no significant correlation with any other percentage changes in abdominal fat compartments or with liver fat.

\section{Changes in dietary intake and in physical activity}

For the dietary stabilization for the inpatient tests, the mean energy intakes were, respectively, 9,705 KJ ( $\mathrm{SE}=467)$ and

Table 2 Fasting incretin hormones and mean AUC for mixed meal variables for eight subjects

\begin{tabular}{|c|c|c|c|c|}
\hline Mixed meal variable & $\begin{array}{l}\text { Pre-roflumilast, } \\
\text { mean (SE) }\end{array}$ & $\begin{array}{l}\text { Post-roflumilast, } \\
\text { mean (SE) }\end{array}$ & $\begin{array}{l}\text { Mean percentage } \\
\text { change }\end{array}$ & $P$-value \\
\hline Fasting GIP hormone, $\mathrm{pg} / \mathrm{mL}$ & $86.2(11.3)$ & $95.2(14.2)$ & $14.1 \%$ & 0.32 \\
\hline Fasting GLP hormone, $\mathrm{pg} / \mathrm{mL}$ & $1.22(0.28)$ & $\mathrm{I} .34(0.3 \mathrm{I})$ & $31.8 \%$ & 0.76 \\
\hline Glucose AUC & $20,977(904)$ & $21,193(1143)$ & $+1.03 \%$ & 0.78 \\
\hline C-peptide AUC & $\mathrm{I}, 793(34 \mathrm{I})$ & $\mathrm{I}, 900(4 \mathrm{II})$ & $+5.97 \%$ & $0.48 *$ \\
\hline GIP hormone AUC & $94,74 \mid(9 \mid 75)$ & $94,819(19620)$ & $+0.08 \%$ & 0.99 \\
\hline GLP-I hormone AUC & $823(137)$ & $\mathrm{I}, 44 \mathrm{I}(4 \mathrm{I})$ & $+75.1 \%$ & 0.18 \\
\hline
\end{tabular}

Notes: Mean AUC for insulin was not assessed due to several hemolyzed samples that had to be excluded from the analysis. $* P$-value as determined using Related SamplesWilcoxon Signed Rank Test. All other $P$-values are from paired $t$-test analysis.

Abbreviations: AUC, area under the curve; GIP, glucose-dependent Insulinotropic polypeptide or gastric inhibitory peptide; GLP, glucagon like peptide.

A

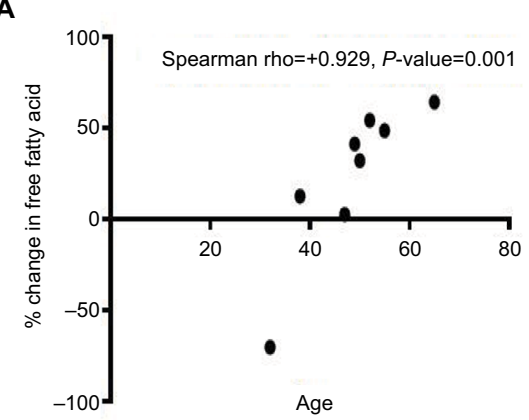

D

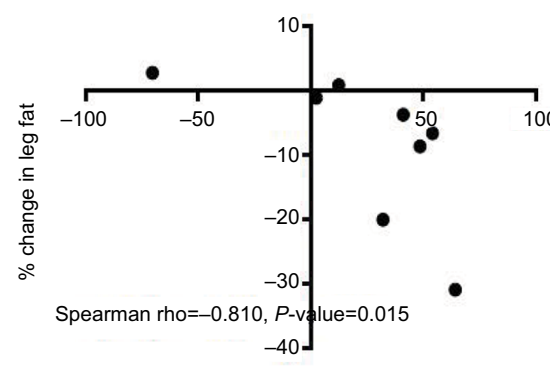

$\%$ change in free fatty acid
B

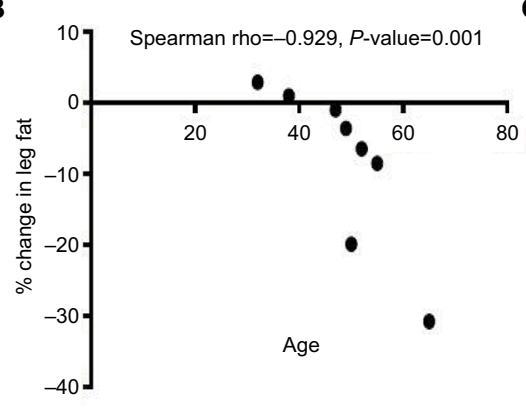

E

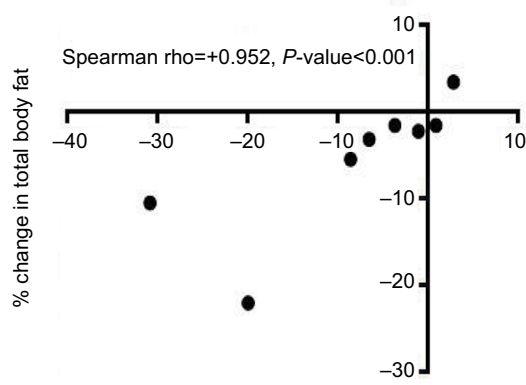

$\%$ change in leg fat

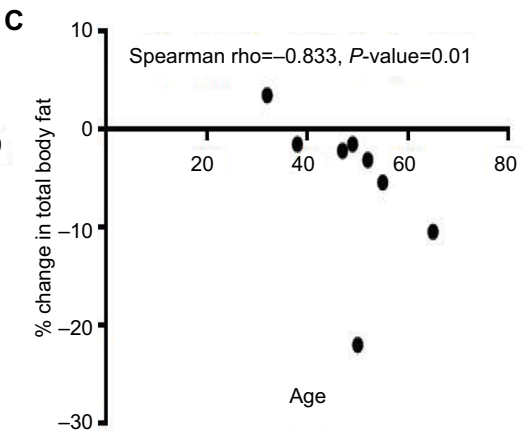

F

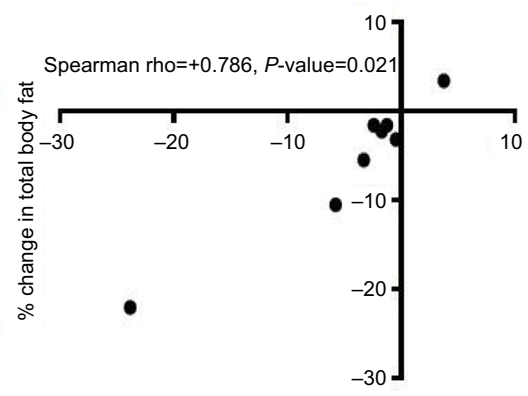

$\%$ change in trunk fat

Figure 2 Spearman correlation demonstrating the age-associated effects of roflumilast on plasma free fatty acids and on fat mass loss. (A-D). The observed significant correlations ( $\mathbf{E}$ and $\mathbf{F}$ ) suggest that a majority of the changes in total body fat appears to stem from relative changes in fat mass in the leg and trunk regions. 
$10,038 \mathrm{KJ}(\mathrm{SE}=451)$ pre- and post-roflumilast. Table 5 summarizes the data from the subjects' food records. All records considered reliable by nutrition staff were used for analysis, regardless of whether or not the subjects subjectively reported their intake as more or less than typical. There was a trend toward a significant decrease in overall energy intake
$(P=0.07)$. Six of the eight subjects reported symptoms that could alter their food intake. These symptoms were transient nausea, decreased appetite, increased appetite, and early satiety. The three subjects who reported decreased appetite reported this symptom within the first 3 weeks on the medication. For the physical activity, we had paired accelerometer

Table 3 Mean abdominal and liver fat $(n=8)$ and leg muscle fat content $(n=5)$ on MRI/MRS

\begin{tabular}{|c|c|c|c|}
\hline Fat region & $\begin{array}{l}\text { Pre-roflumilast, } \\
\text { mean (SE) }\end{array}$ & $\begin{array}{l}\text { Post-roflumilast, } \\
\text { mean (SE) }\end{array}$ & $P$-value \\
\hline \multicolumn{4}{|c|}{ A) Body compartment on DXA } \\
\hline Total fat, in kg & $34.53(2.74)$ & $32.97(3.10)$ & 0.06 \\
\hline Trunk fat, in kg & $20.32(1.93)$ & $19.63(2.11)$ & 0.13 \\
\hline Visceral fat, in $\mathrm{kg}$ & $\mathrm{I} .87(0.26)$ & I.7I $(0.26)$ & 0.08 \\
\hline Lean mass, in $\mathrm{kg}$ & $59.95(4.1 \mathrm{I})$ & $59.47(4.10)$ & 0.41 \\
\hline \multicolumn{4}{|c|}{ B) Abdominal compartment on MRI } \\
\hline L2-L3 subcutaneous fat & $263(32)$ & $258(3 I)$ & 0.41 \\
\hline L4-L5 subcutaneous fat & $36 I(3 I)$ & $352(38)$ & 0.45 \\
\hline L2-L3 visceral fat & $224(33)$ & $194(31)$ & 0.03 \\
\hline L4-L5 visceral fat & $178(25)$ & $155(31)$ & 0.09 \\
\hline Liver fat (in \%) & $5.9(\mathrm{I} . \mathrm{I})$ & $5.2(1.3)$ & $0.5 \mathrm{I}$ \\
\hline \multicolumn{4}{|c|}{ C) Leg muscle compartment on MRI/MRS } \\
\hline Lateral vastus EMCL & $26.7(4.9)$ & $24.4(6.7)$ & 0.57 \\
\hline Soleus EMCL & $47.5(2.6)$ & $59.4(14.3)$ & $0.345^{*}$ \\
\hline Lateral vastus IMCL & $6.4(1.5)$ & $4.5(1.6)$ & 0.41 \\
\hline Soleus IMCL & $38.9(16.2)$ & $18.5(5.1)$ & 0.18 \\
\hline
\end{tabular}

Notes: The MRI/MRS numerical values are ratio-based and, thus, have no units of measurements. *P-value as determined using Related Samples-Wilcoxon Signed Rank Test. All other $P$-values are from paired $t$-test analysis.

Abbreviations: DXA, dual energy x-ray absorptiometry; EMCL, extramyocellular lipid; IMCL, intramyocellular lipid; MRI, magnetic resonance imaging; MRS, magnetic resonance spectroscopy.

Table 4 Relative changes in lower extremity muscle fat by local fat compartment

\begin{tabular}{|l|l|l|l|}
\hline $\begin{array}{l}\text { Lower extremity } \\
\text { muscle assessed }\end{array}$ & $\begin{array}{l}\text { Mean \% change } \\
\text { in EMCL }\end{array}$ & $\begin{array}{l}\text { Mean \% change } \\
\text { in IMCL }\end{array}$ & $\begin{array}{l}\text { Mean \% change in the } \\
\text { muscle's total lipid content }\end{array}$ \\
\hline Soleus & $+24 \%$ & $-39 \%$ & $-9.6 \%$ \\
\hline Vastus Lateralis & $+11 \%$ & $-23 \%$ & $-16 \%$ \\
\hline
\end{tabular}

Notes: Percentage changes was determined (difference between post-roflumilast and pre-roflumilast multiplied by $100 \%$ and then divided by pre-roflumilast value) for each subject and then averaged to obtain mean percentage changes.

Abbreviations: EMCL, extramyocellular lipid; IMCL, intramyocellular lipid.

Table 5 Mean dietary composition as quantified by the subjects in their food records ("a") and mean serum lipid profile ("b") before and after roflumilast

\begin{tabular}{|c|c|c|c|}
\hline & $\begin{array}{l}\text { Pre-roflumilast, } \\
\text { mean (SE) }\end{array}$ & $\begin{array}{l}\text { Post-roflumilast, } \\
\text { mean (SE) }\end{array}$ & P-value \\
\hline \multicolumn{4}{|c|}{ a) Total energy and nutrient composition from food records, units of measurement } \\
\hline Total Energy, Kilojoules (KJ) & $\mathrm{II}, 095(812)$ & $8,455(852)$ & $0.07^{*}$ \\
\hline$\%$ energy from fat & $33.6(3.0)$ & $31.8(2.7)$ & 0.64 \\
\hline$\%$ energy from carbohydrates & $48.3(3.7)$ & $49.3(2.7)$ & 0.71 \\
\hline$\%$ energy from protein & $17.7(2.2)$ & $17.2(1.7)$ & 0.80 \\
\hline \% energy from alcohol & $0.46(0.44)$ & $1.80(1.79)$ & $0.69 *$ \\
\hline \multicolumn{4}{|l|}{ b) Serum lipid profile } \\
\hline Total cholesterol, mg/dL & $193(6.8)$ & $176(9.9)$ & 0.06 \\
\hline HDL cholesterol, mg/dL & $50(5.5)$ & $46(3.0)$ & 0.31 \\
\hline LDL cholesterol, mg/dL & $117(8.1)$ & $105(11.7)$ & 0.06 \\
\hline Triglycerides, mg/dL & $129(11.8)$ & $124(11.0)$ & 0.40 \\
\hline Free fatty acids, $\mathrm{mEq} / \mathrm{L}$ & $0.40(0.07)$ & $0.50(0.13)$ & $0.09 *$ \\
\hline
\end{tabular}

Notes: *P-value as determined using Related Samples-Wilcoxon Signed Rank Test. All other $P$-values are from paired $t$-test analysis.

Abbreviations: HDL, high density lipoproteins; LDL, low density lipoproteins. 
data on six subjects. Analysis of these data revealed no difference in physical activity before and after the roflumilast $(P=0.46)$.

\section{Effect of roflumilast on inflammatory and cellular adhesion markers and on mitochondrial biogenesis}

Mean interval changes in inflammatory and cellular adhesion markers were not significant (Table 6). Nevertheless, several of these markers correlated with one another and with incretin hormones after roflumilast, but not before roflumilast (Figure 3). We observed three constellations of significant correlations involving these markers: 1) among leptin, peripheral insulin sensitivity, adiposity, and GLP-1 (Figure 1), 2) among adiponectin, GIP hormone, and adiposity (Figure 4), and 3) among E selectin, ICAM, and incretin hormones (Figure 3). Correlation of the inflammatory markers using percentage interval changes revealed significant

Table 6 Mean values of inflammatory and adhesion markers before and after roflumilast

\begin{tabular}{|c|c|c|c|}
\hline $\begin{array}{l}\text { Inflammatory and adhesion } \\
\text { markers }\end{array}$ & $\begin{array}{l}\text { Pre-roflumilast, } \\
\text { mean (SE) }\end{array}$ & $\begin{array}{l}\text { Post-roflumilast, } \\
\text { mean (SE) }\end{array}$ & $P$-value \\
\hline TNF- $\alpha, p g / m L$ & $7.34(1.1)$ & $7.50(1.0)$ & $0.83 *$ \\
\hline $\mathrm{MCP}, \mathrm{pg} / \mathrm{mL}$ & $185.9(23)$ & $162.2(24)$ & $0.2 I^{*}$ \\
\hline $\mathrm{Hs}-\mathrm{CRP}, \mathrm{mg} / \mathrm{L}$ & $2.5(0.85)$ & $3.3(0.73)$ & 0.42 \\
\hline VCAM, ng/mL & $1,036(393)$ & $\mathrm{I}, 065(406)$ & $0.16^{*}$ \\
\hline ICAM, ng/mL & $439(50)$ & $45 I(55)$ & 0.57 \\
\hline E-selectin, pg/mL & 28,55 I (3I95) & $30,247(3686)$ & 0.40 \\
\hline Adiponectin, $\mathrm{ng} / \mathrm{mL}$ & $4,949(542)$ & $4,468(444)$ & 0.15 \\
\hline Leptin, pg/mL & 28,957 (7|42) & $25,763(8 \mid 4 I)$ & 0.20 \\
\hline
\end{tabular}

Notes: *P-value as determined using Related Samples-Wilcoxon Signed Rank Test. All other $P$-values are from paired $t$-test analysis.

Abbreviations: HS CRP, high sensitivity C reactive protein; ICAM, intracellular adhesion molecule; MCP, monocyte chemoattractant protein; TNF, tumor necrosis factor; VCAM, vascular cell adhesion molecule.

A

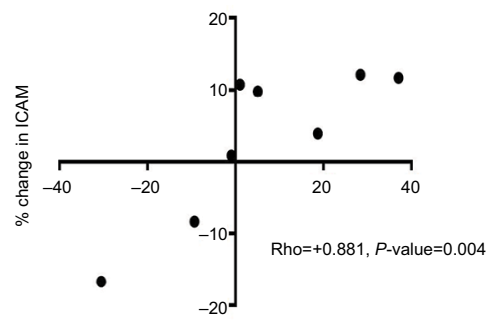

$\%$ change in E-selection

D

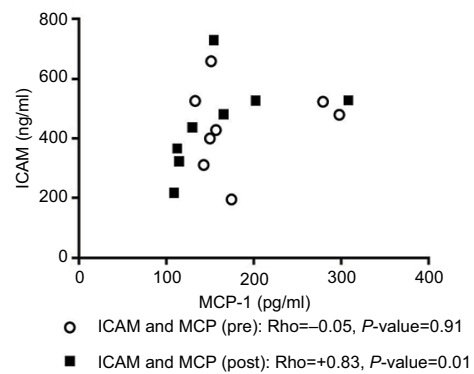

B

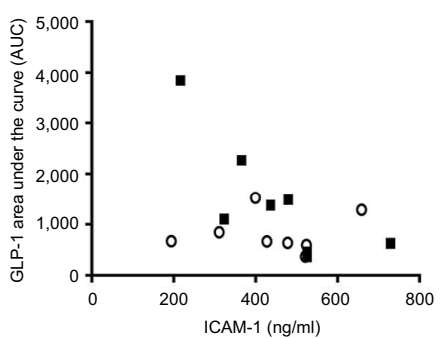

○ GLP AUC and ICAM (pre): Rho $=-0.333, P$-value $=0.42$

- GLPAUC and ICAM (post): Rho $=-0.738, P$-value $=0.037$

E

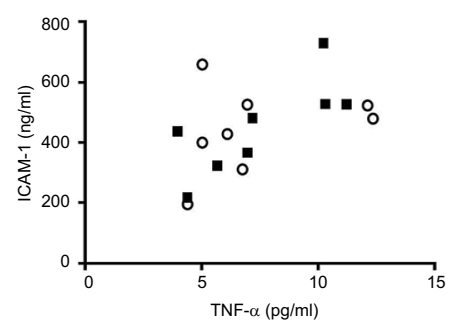

- ICAM and TNF- $\alpha$ (pre): Rho $=+0.395, P$-value $=0.33$

- ICAM and TNF- $\alpha$ (post): $R$ ho $=+0.762, P$-value $=0.028$
C

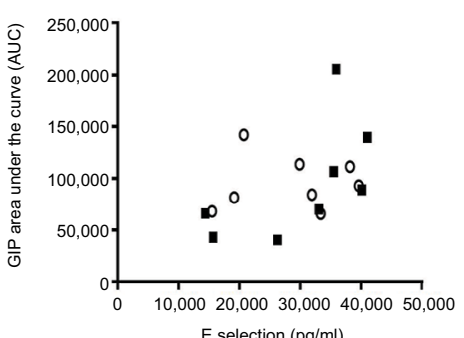

O GIP AUC and E selection (pre): Rho $=+0.143, P$-value $=0.736$

1 GIP AUC and E selection (post): Rho $=+0.786, P$-value $=0.021$

$\mathbf{F}$

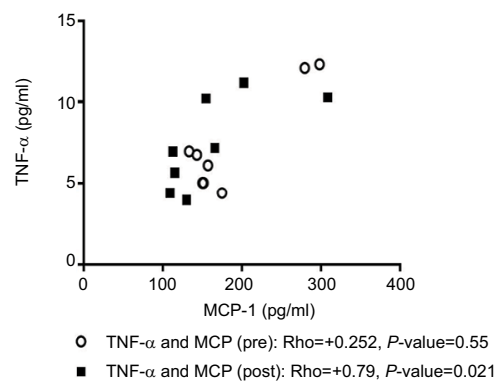

Figure 3 Roflumilast induced changes among incretin hormones, inflammatory, and adhesion markers with statistical significance fall within a constellation. Both interval changes in ICAM and E-selectin were associated (A). After roflumilast but not before roflumilast, ICAM and GLP-I (B) and E-selectin and GIP (C) were significantly associated. After roflumilast but not before roflumilast, ICAM is also significantly associated with MCP and TNF- $\alpha$ (D and E).

Abbreviations: AUC, area under the curve; GIP, glucose-dependent insulinotropic polypeptide or gastric inhibitory peptide; GLP, glucagon-like peptide; ICAM, intracellular adhesion molecule; MCP, monocyte chemoattractant protein; TNF, tumor necrosis factor. 
correlation only with the E-selectin and ICAM pair (Figure $3 \mathrm{~A}$ ). We found no statistically significant effect of roflumilast on mitochondrial biogenesis of the polymorphonuclear blood cells $(P=0.14)$.

\section{Adverse events, effects of roflumilast on routine physical and laboratory tests}

Subjects were compliant with roflumilast, as determined by pill count. Roflumilast was generally well tolerated. Drugrelated adverse effects were mild-to-moderate and included insomnia, irritability, headache, nausea, loose stools, changes in appetite, musculoskeletal pain, and fatigue (Table 7). Subjects had no significant changes in their vital signs and routine laboratory tests (Table S2, Supplementary materials). We observed a trend toward a significant decrease in total cholesterol and LDL cholesterol ( $P=0.06$ for both variables). The percentage changes between total and LDL cholesterol were highly correlated (Rho $=0.93, P=0.001$ ), thus suggesting that the changes in LDL cholesterol may account for a majority of the observed changes in total cholesterol. Fasting plasma free fatty acids also increased, although not significantly $(P=0.09)$. Fasting triglyceride and HDL cholesterol levels were unchanged (Table 5).

\section{Discussion}

In this study, we did not observe any roflumilast-induced improvement in our primary outcome, peripheral insulin sensitivity, as assessed using the clamp study's M value. However, this negative finding must be interpreted with caution, given that this study is underpowered for the primary outcome. A clinical study determined that a change in $\mathrm{M}$

Table 7 Study-related adverse effects reported by subjects who took roflumilast (the report is for all nine subjects who took roflumilast)

\begin{tabular}{|l|l|}
\hline Reported adverse effects & $\begin{array}{l}\text { Number of subjects } \\
\text { reporting symptoms }\end{array}$ \\
\hline Diarrhea & 2 \\
\hline Nausea & $\mathrm{I}$ \\
\hline Dyspepsia & $\mathrm{I}$ \\
\hline Weight loss of greater than 5\% & $\mathrm{I}$ \\
\hline Fatigue & 2 \\
\hline Dizziness & $\mathrm{I}$ \\
\hline Insomnia & 4 \\
\hline Irritability & 2 \\
\hline Pruritis & $\mathrm{I}$ \\
\hline Neck pain & $\mathrm{I}$ \\
\hline Tremor & $\mathrm{I}$ \\
\hline Headache & 4 \\
\hline
\end{tabular}

A

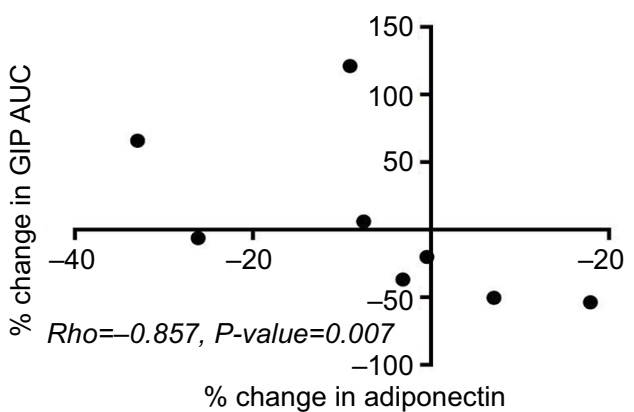

C

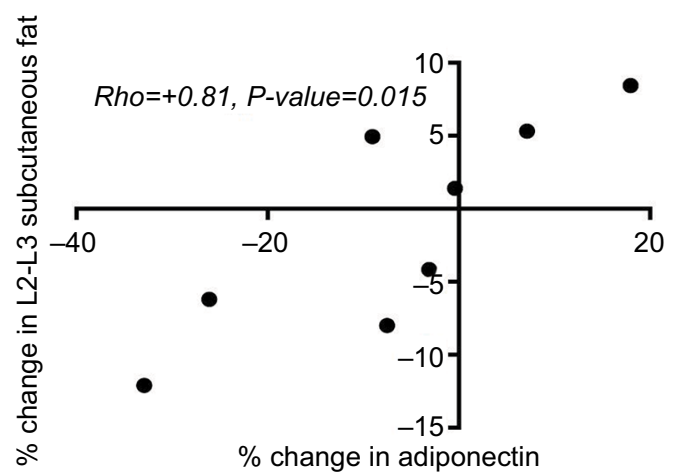

B

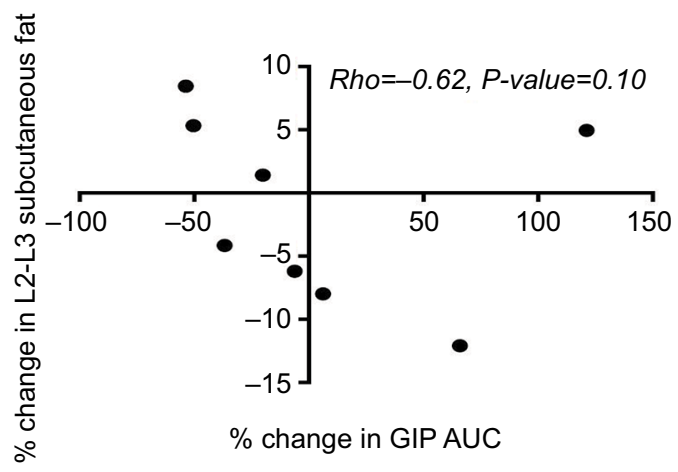

D

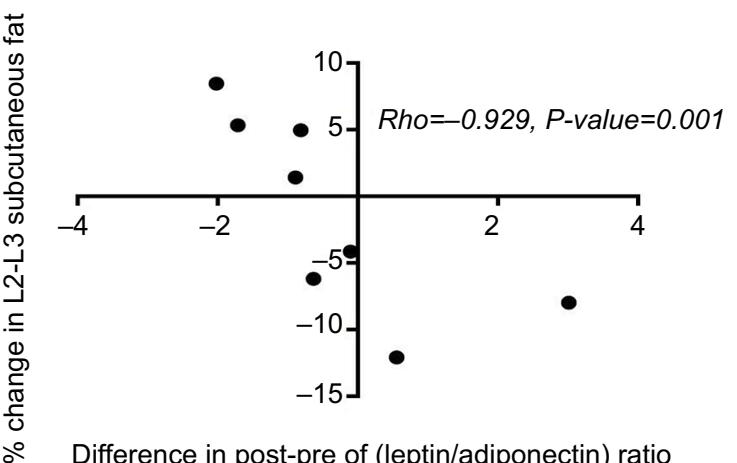

Figure 4 Spearman correlation demonstrating the significant associations among percentage changes in GIP hormone, adiponectin, and lumbar subcutaneous adiposity (A-D). Roflumilast induced change in lumbar subcutaneous adiposity is much more significantly associated with roflumilast-induced changes in the leptin and adiponectin ratio (D) than in interval changes in adiponectin ratio alone (C).

Abbreviations: AUC, area under the curve; GIP, glucose-dependent insulinotropic polypeptide or gastric inhibitory peptide. 
value of $20 \%$ or greater correlated with a clinically important change in peripheral insulin sensitivity. ${ }^{39}$ Thus, despite the statistical non-significance in our primary outcome, it is worth noting that six out of the seven subjects with paired clamp data achieved at least a $20 \%$ increase, from baseline, in their $M$ values, and that the average change in $M$ value was $46 \%$. Hence, the statistically negative finding of our primary outcome, which we attribute to our small sample size, ought not deter future mechanistic studies of the effects of roflumilast on insulin sensitivity.

A large clinical trial which provided 3 months of roflumilast to subjects with Type 2 diabetes mellitus demonstrated improved diabetes control by using hemoglobin A1c and fasting glucose data. ${ }^{22}$ In that study, the researchers found decreased postprandial free fatty acids and glucagon levels and speculated on incretins' role in their reported findings. ${ }^{22}$ In this study, we provided subjects with 6 weeks of roflumilast, and used correlation analysis to directly implicate incretins in roflumilast's early metabolic effects for the first time in humans. While we found no significant changes in the mean incretin AUC with roflumilast, our analysis revealed significant correlations among roflumilastassociated changes in incretins, insulin sensitivity, adiposity, and the adipocytokines - leptin and adiponectin. These correlations directly implicate incretins in roflumilast's mechanism of action and may help to explain why PDE4 enzyme's anti-lipolytic effects depended on nutritional state (fasting vs postprandial) and on whether or not insulin was present. ${ }^{26}$ Thus, using an enzyme inhibitor, we show a novel concept that PDE4 enzyme is a key link between inflammatory cells and energy stores and that incretins facilitate this link. This finding could prove critical in our understanding of the inflammation involved in postprandial lipemia. It is also noteworthy that, in this study, the atherogenic lipid profile improved, and the improvement trended toward statistical significance. Large scale epidemiologic studies demonstrate decreased prevalence of cardiovascular events in patients with COPD who take roflumilast, ${ }^{41}$ thereby suggesting that roflumilast may, indeed, have antiatherogenic benefits in patients with high cardiovascular event risk. Considering that roflumilast induces an incretin effect in mice and decreases post prandial free fatty acids levels in adults with insulin resistance, ${ }^{22,30,42,43}$ a GLP-1 mediated decrease in postprandial lipemia ${ }^{44,45}$ is a possible mechanism for the improved lipid profile. Further studies are, therefore, needed to elucidate the mechanistic link among PDE4 enzymes, incretin hormones, and free fatty acid flux in various bodily systems.
In the skeletal muscles, large influx of free fatty acids induces insulin resistance easily and robustly by reducing intracellular insulin signaling. ${ }^{46}$ When IMCL is reduced in subjects with insulin resistance, their muscle insulin sensitivity improves in some but not all lower extremity muscle groups. ${ }^{46}$ In subjects with obesity and insulin resistance, acute caloric restriction significantly decreases IMCL in soleus muscle and improves peripheral insulin sensitivity, even before significant loss of adiposity occurs. ${ }^{47}$ Thus, the observed relative decrease in IMCL (Table 4) likely reflects roflumilast's known increased lipolytic action in skeletal muscles. ${ }^{11,48}$ The observed relative increase in EMCL likely reflects increased fatty acid supply from the adipose tissue due to roflumilast's induced increase in adipose tissue lipolysis $^{26}$ and the sequestering of these fatty acids into the extra-myo-cellular space to avoid intracellular lipo-toxicity. The correlation of insulin sensitivity with adiposity makers (Figures $1 \mathrm{E}$ and $\mathrm{F}$ ) demonstrates that inter-individual variations in lipid metabolism likely contribute to varying time points for clinically improved insulin sensitivity. This correlation, in addition to the unchanged average insulin sensitivity, may indicate that the time to clinically improved insulin sensitivity depends on the degree of baseline tissue lipotoxicity.

Given that free fatty acids can cause insulin resistance, ${ }^{46}$ the ability to control free fatty acid flux into the skeletal muscle could, therefore, be one way to maintain peripheral insulin sensitivity. Among the coordinated roles of GLP-1 hormone is to increase microvascular flow to peripheral tissues such as the muscles. ${ }^{49}$ In this study, we observed differences in the degree of association among the incretin hormones and the IMCL/EMCL in the limb muscles assessed. This finding may suggest that the link between PDE4 enzymes and incretin hormones influence free fatty acid flux in the skeletal muscles. In mice, the highly oxidative soleus muscle has over a ten-fold greater PDE4 activity than the less oxidative tibialis anterior muscle. ${ }^{50}$ Accordingly, the soleus muscle may be physiologically positioned to manifest the greatest magnitude of roflumilast's effect. Thus, the observed significant association of changes in soleus muscle's EMCL with changes in GLP-1 may suggest a mechanistic link - that is, GLP-1's induced increase in microvascular flow $^{49}$ permits preferential delivery of fat to the more oxidative soleus muscles. It is interesting that, in our study, the two subjects with an interval decrease in GLP-1 AUC both had over a 50\% increase in their soleus muscle EMCL. While this correlation does not necessarily indicate causality, the possibility of a lipid threshold for negative feedback control 
of GLP-1 release must be entertained..$^{51}$ The significant association between the change in L2-L3 visceral adiposity with the change in soleus EMCL may also suggest that these two visceral adipose sites are equally physiologically linked. The observed reduced adiposity in the waist - that is within the L2-L5 region - sparks a reminder of L2-L5 spinal nerves' myotome and dermatome distribution as well as of the interconnected sympathetic nerves and lumbar plexus in the waist. Additionally, PDE4 enzymes are abundant in the human brain, particularly in brain regions which control skeletal muscle movements and movements within visceral tissues..$^{52}$ Thus, from an integrated biology viewpoint, roflumilast, via downstream beta-adrenergic signaling, ${ }^{50}$ may also be a physical exercise mimetic that increases abdominal fat and gait muscles' lipolysis. While it is known that PDE4 inhibition improves exercise performance in mice, ${ }^{11}$ studies are needed in humans to demonstrate this possibility and to confirm the observed correlations.

In the setting of physical exercise, age is a critical determinant of the level of the free fatty acids that is released from the adipose tissue. Despite having adequate systemic catecholamines, older individuals release less free fatty acids from their adipose tissue than younger individuals during exercise. ${ }^{53}$ Recent research pinpoints the age-associated decrease in lipolysis to be due to NLRP3 inflammasomemediated changes in macrophages which reduce adipose tissue catecholamine levels. ${ }^{54}$ In this study, we observed significant associations involving age, plasma free fatty acid level and percentage changes in total body and leg fat content. These strong associations lead us to hypothesize that roflumilast's induced increase in adipose tissue lipolysis with increasing age is due to an over-riding of the reduced adipose tissue's beta adrenergic effect with age. We postulate that the observed age-associated benefits of roflumilast occurs because, as a result of "inflammaging", 55 older individuals have greater PDE4 enzyme activity than their younger counterparts, and, hence, stand to experience a relatively greater cAMP increase from roflumilast than their younger counterparts. Our correlation findings suggest that older individuals with overweight/obesity may stand to benefit more than their younger counterparts from the weight loss effects of roflumilast. At the same time, in the presence of baseline insulin resistance, ${ }^{56}$ a roflumilast-induced increase in free fatty acid flux to the skeletal muscle could be more deleterious for insulin signaling in older adults than in their younger counterparts, particularly if the increased adipose tissue lipolysis was not coupled with sufficiently increased skeletal muscle lipolysis. Further studies, preferably large scale and longitudinal in nature, are needed to elucidate the combined effects of age and the severity of 1) lifestyle habits, 2) adiposity, and 3) skeletal muscle mitochondrial dysfunction on the time to overt manifestation of roflumilast's effect on insulin sensitivity.

As other published studies on roflumilast and insulin resistance demonstrated weight loss with 3 months use of roflumilast, ${ }^{20,22}$ we embarked on 6-weeks use of roflumilast in order to reduce the weight loss confounding effect of roflumilast on insulin sensitivity. Despite the shortened drug exposure, we observed a trend toward significance in decreased total energy intake and in loss of fat mass, particularly in the visceral adipose region. It is conceivable that roflumilast's effect on energy intake is centrally mediated, possibly indirectly, via GLP-1 signaling to the hypothalamus, given that human hypothalamic structures lack PDE4 enzyme. ${ }^{52}$ Roflumilast's induced increase in GLP-1 ${ }^{30,42}$ could improve insulin sensitivity either through an incretin effect ${ }^{57}$ and/or through loss of adiposity. ${ }^{58}$ Among the mixed meal variables assessed in this study, roflumilast altered GLP-1 AUC the most. At the same time, in published trials, roflumilast induced a mean $2 \mathrm{~kg}$ weight loss over 3 months in subjects with insulin resistance. ${ }^{20,22}$ In light of these findings, longitudinal studies are, therefore, needed to determine what early metabolic effects of roflumilast are sustained over time, and what new compensatory effects appear with time.

In this study, we found no evidence of a roflumilastinduced decrease in systemic inflammation and of interval change in mitochondrial biogenesis in the peripheral blood cells of our subjects. Potential reasons for these findings include the small sample size, short study duration, type of immune cells assessed, and the peripheral sampling of these cells as opposed to sampling from specific tissues. The significant correlation of interval changes in E-selectin and ICAM is consistent with prior published findings of roflumilast's inhibitory effect on the inflammatory cascade..$^{59}$ The association of some of the inflammatory and adhesion markers with one another only at the 6 weeks timepoint (Figures 3D-F) could highlight anatomic and mechanistic areas of the inflammatory cascade where the effect of roflumilast is dynamic. Through our novel significant correlations, we demonstrate that modulation of the adipose tissue specific cytokines - leptin and adiponectin - are involved in roflumilast's early metabolic effects. Furthermore, leptin and adiponectin play crucial roles in oxidative stress, inflammation, and insulin resistance. ${ }^{60,61}$ PDE4 inhibitors can activate the muscle's antioxidant system, and such an effect would be expected to counteract oxidative stress and help prevent myo- 
cyte death. ${ }^{62}$ Thus, given our study's association of changes in subcutaneous abdominal fat with 1) changes in adiponectin and 2) the post-pre difference in the leptin-to-adiponectin ratio, further studies are needed to determine whether or not these changes reflect roflumilast-induced improvement in skeletal muscle health.

Our study has various strengths and weakness. A major strength of this study is its exploratory design with simultaneous assessment of many variables of interest. In this understudied research area, the combined use of this study design with a clinically acceptable PDE4 inhibitor yielded many results that could be pieced together to gain some insights into PDE4 enzyme's role in obesity and prediabetes' pathophysiology. The various hypotheses generated from this exploratory study, therefore, could help to guide future studies and, thereby, help to accelerate the narrowing of the currently wide knowledge gap in this research area. Second, we sought out to minimize the weight loss confounding effect by using a short study duration. Third, we used dietary stabilization to minimize dietary effects on outcomes. Fourth, through our constellational correlations, we showed molecules that likely employ PDE4 enzyme downstream of their receptor signaling. Despite our study strengths, our study has various limitations. First, the study is underpowered for its primary outcome variable. Second, the novel correlations in this study provide a metabolic overview that needs to be delved into with additional studies. Third, we cannot definitively rule out the possibility that observational bias (lifestyle modification) contributed to the observed outcomes. Fourth, food record data is prone to error as it depends on the subject's engagement in the data collection. Fifth, statin, although chronically prescribed in our two study subjects, could have affected the inflammatory markers and lipid profile. ${ }^{63}$ Sixth, the inherent technical limitations of our study procedures led to an incomplete dataset on some of the study variables. Seventh, we lack cellular data on the tissue-specific effects of roflumilast in humans including which PDE4 isoforms best explain each constellation of correlations. Lastly, our findings may not be generalizable to other PDE4 inhibitors or to other similar studies with different end timepoints or subject panel.

We conclude that the published finding of roflumilastinduced improvement in insulin sensitivity in subjects with insulin resistance ${ }^{22}$ most likely occurred through various mechanisms. These possible early mechanisms include a reduction in adiposity either due to roflumilast's induced increase in skeletal muscle fat oxidation ${ }^{48}$ or via an increase in GLP-1. It is quite possible that changes in
GLP-1 hormone drive several of the mechanisms such as on energy intake and on insulin secretion. In this study, we demonstrate a novel link, in humans, among PDE4 enzyme, incretin hormones, fat handling, and inflammatory markers through our constellation of significant roflumilast-induced correlations. We also demonstrate a novel association between age and roflumilast's induced changes in fat mass in humans. Given that the cellular perturbations in both obesity and in aging reduce AMPK ${ }^{14,64}$ and trigger inflammation, ${ }^{55}$ we propose that PDE4 enzymes play a central role in the pathophysiology of the metabolic diseases seen in both obesity and aging (Figure 5). By increasing cAMP to increase AMPK, PDE4 inhibitors such as roflumilast stand to modify the sentinel cellular perturbations in both obesity and aging by targeting mitochondrial function, ${ }^{11}$ oxidative stress, and tissue inflammation. ${ }^{9,33}$ Thus, the potential to uncover another therapy with the pleiotropic benefits of GLP-1 agonists needs further investigation. Given the currently limited medical options for the simultaneous treatment of several cardiometabolic conditions in persons aging with obesity, future research would need to be prioritized to the potential of repurposing certain FDA-approved medications with acceptable long-term side-effect profiles for use in the treatment of obesity and its associated cardiometabolic diseases.

\section{Abbreviations}

AMPK, AMP-activated protein kinase; cAMP, Cyclic AMP; COPD, chronic obstructive pulmonary disease; HS, CRP, high sensitivity $\mathrm{C}$ reactive protein; EMCL, extramyocellular lipid; FDA, Food and Drug Administration; GLP-1, glucagon like peptide 1; GIP, glucose-dependent insulinotropic polypeptide or gastric inhibitory peptide; $\mathrm{HbA1c}$, glycosylated haemoglobin; ICAM, intracellular adhesion molecule; IMCL, intramyocellular lipid; MCP, monocyte chemoattractant protein; MRI, magnetic resonance imaging; MRS, magnetic resonance spectroscopy; PDE4, phosphodiesterase 4; TNF, tumor necrosis factor; VCAM, vascular cell adhesion molecule 1.

\section{Data sharing statement}

De-identified data results can be shared electronically with qualified investigators after all involved parties complete all necessary formal data request approval processes and executive agreements in accordance with the rules and regulations of their respective institutions. Beginning at 3 months after the publication of the manuscript, the authors can be contacted to request the de-identified data. The data will be available for request for 6 months. 


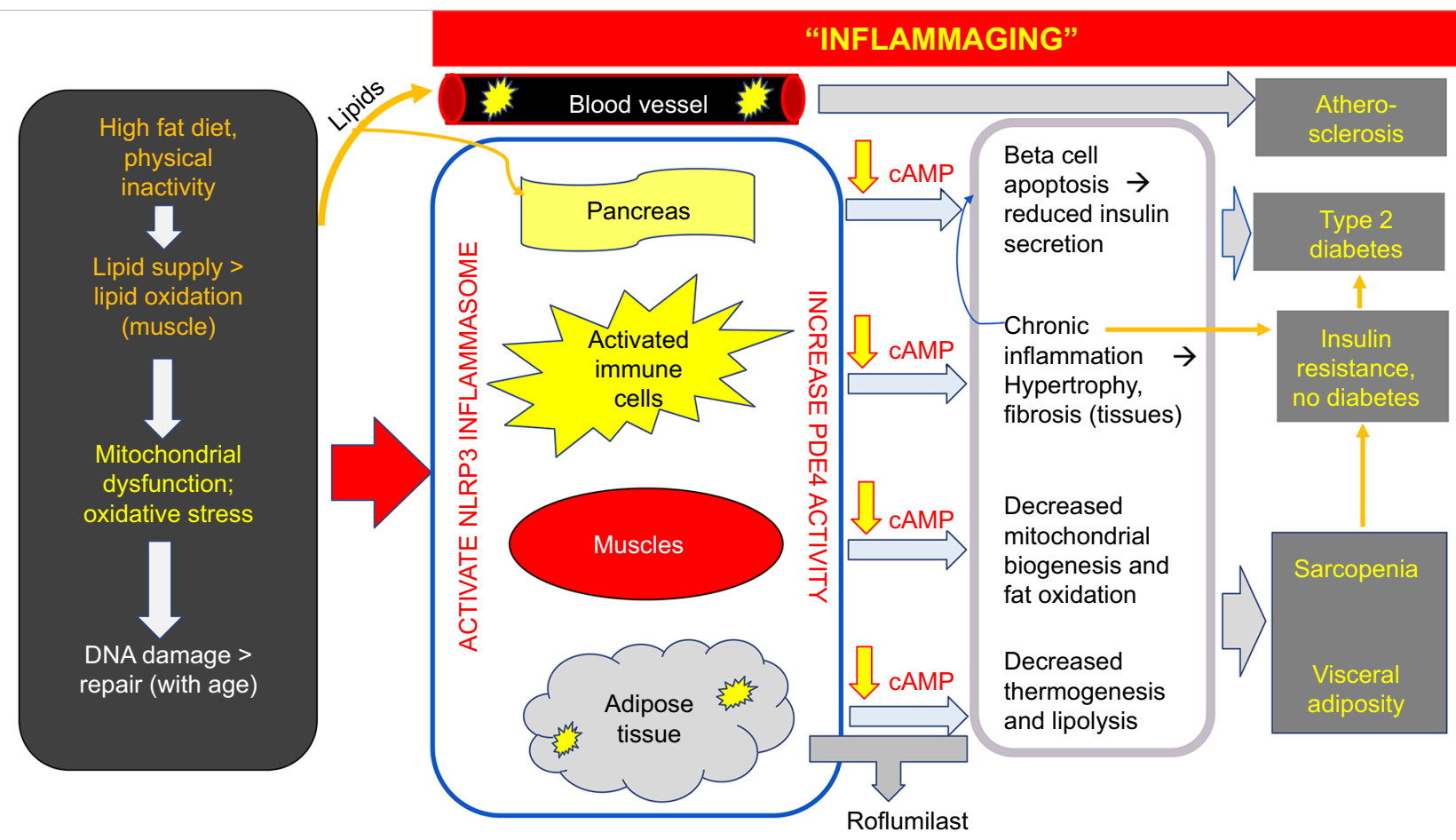

Figure $\mathbf{5}$ Working hypothesis for roflumilast's age-associated beneficial changes in body composition.

Abbreviation: cAMP, cyclic AMP.

\section{Acknowledgments}

The authors would like to thank: 1) Peter J Schmidt, MD (NIMH, NIH) for his administrative role with the psychiatric portion of the study; 2) Eunice Kennedy Shriver National Institute of Child Health and Human Development at National Institutes of Health for their salary support to IMM during her involvement in the study as an endocrine fellow 3) Megan Startzel, RN (NIDDK, NIH) for her help with the glucose clamp procedures; and 4) All of the exercise physiologists, nurses and staff at NIH's metabolic unit as well as the pharmacists at the NIH's clinical center. This work was supported by the Intramural Research Program, National Heart, Lung, Blood Institute, and National Institute of Diabetes and Digestive and Kidney Diseases, National Institutes of Health. The study sponsor (NIH) provided protocol review, funding, personnel, facility, and pharmaceutical assistance. The study's research plan was presented at the Endocrine Fellows' Foundation research meeting in Texas, USA in January 2016. The current affiliation of RM is the Medical College of Wisconsin, Milwaukee, WI, USA.

\section{Author contributions}

All authors contributed towards analyzing the data, drafting and revising the paper, gave final approval of the version to be published and agreed to be accountable for all aspects of the work.

\section{Disclosure}

The authors report no conflicts of interest in this work.

\section{References}

1. Dandona P, Ghanim H, Chaudhuri A. Incretins: beyond type 2 diabetes. Diabetes Obes Metab. 2018;20(7349):59-67.

2. FLAT-SUGAR Trial Investigators. Glucose variability in A 26-week randomized comparison of mealtime treatment with rapid-acting insulin versus GLP-1 agonist in participants with type 2 diabetes at high cardiovascular risk. Diabetes Care. 2016;39(6):973-981.

3. McNelis JC, Olefsky JM. Macrophages, immunity, and metabolic disease. Immunity. 2014;41(1):36-48.

4. Houstis N, Rosen ED, Lander ES. Reactive oxygen species have a causal role in multiple forms of insulin resistance. Nature. 2006;440(7086):944-948.

5. Wong E, Tanamas SK, Wolfe R, et al. The role of obesity duration on the association between obesity and risk of physical disability. Obesity. 2015;23(2):443-447.

6. Adams KF, Schatzkin A, Harris TB, et al. Overweight, obesity, and mortality in a large prospective cohort of persons 50 to 71 years old. $N$ Engl J Med. 2006;355(8):763-778.

7. Burkewitz K, Zhang Y, Mair WB. AMPK at the nexus of energetics and aging. Cell Metab. 2014;20(1):10-25.

8. Mottillo EP, Desjardins EM, Crane JD, et al. Lack of adipocyte AMPK exacerbates insulin resistance and hepatic steatosis through brown and beige adipose tissue function. Cell Metab. 2016;24(1):118-129.

9. Mancini SJ, White AD, Bijland S, et al. Activation of AMP-activated protein kinase rapidly suppresses multiple pro-inflammatory pathways in adipocytes including IL-1 receptor-associated kinase-4 phosphorylation. Mol Cell Endocrinol. 2017;440:44-56.

10. Meng W, Liang X, Chen H, et al. Rheb inhibits beiging of white adipose tissue via PDE4D5-dependent downregulation of the cAMP-PKA signaling pathway. Diabetes. 2017;66(5):1198-1213. 
11. Park SJ, Ahmad F, Philp A, et al. Resveratrol ameliorates aging-related metabolic phenotypes by inhibiting cAMP phosphodiesterases. Cell. 2012;148(3):421-433.

12. Wang P, Zhang RY, Song J, et al. Loss of AMP-activated protein kinase- $\alpha 2$ impairs the insulin-sensitizing effect of calorie restriction in skeletal muscle. Diabetes. 2012;61(5):1051-1061.

13. Sylow L, Møller LLV, Kleinert M, et al. Rac1 and AMPK account for the majority of muscle glucose uptake stimulated by ex vivo contraction but not in vivo exercise. Diabetes. 2017;66(6):1548-1559.

14. Xu XJ, Gauthier MS, Hess DT, et al. Insulin sensitive and resistant obesity in humans: AMPK activity, oxidative stress, and depotspecific changes in gene expression in adipose tissue. J Lipid Res. 2012;53(4):792-801.

15. Xu XJ, Apovian C, Hess D, Carmine B, Saha A, Ruderman N. Improved insulin sensitivity 3 months after RYGB surgery is associated with increased subcutaneous adipose tissue AMPK activity and decreased oxidative stress. Diabetes. 2015;64(9):3155-3159.

16. Rogliani P, Calzetta L, Cazzola M, Matera MG. Drug safety evaluation of roflumilast for the treatment of COPD: a meta-analysis. Expert Opin Drug Saf. 2016;15(8):1133-1146.

17. Keating GM. Apremilast: a review in psoriasis and psoriatic arthritis. Drugs. 2017;77(4):459-472.

18. Fabbri LM, Calverley PMA, Izquierdo-Alonso JL, et al. Roflumilast in moderate-to-severe chronic obstructive pulmonary disease treated with longacting bronchodilators: two randomised clinical trials. Lancet. 2009;374(9691):695-703.

19. Tannheimer SL, Wright CD, Salmon M. Combination of roflumilast with a beta-2 adrenergic receptor agonist inhibits proinflammatory and profibrotic mediator release from human lung fibroblasts. Respir Res. 2012;13(1):28.

20. Jensterle M, Kocjan T, Janez A. Phosphodiesterase 4 inhibition as a potential new therapeutic target in obese women with polycystic ovary syndrome. J Clin Endocrinol Metab. 2014;99(8):E1476-E1481.

21. Jensterle M, Salamun V, Kocjan T, Vrtacnik Bokal E, Janez A. Short term monotherapy with GLP-1 receptor agonist liraglutide or PDE 4 inhibitor roflumilast is superior to metformin in weight loss in obese PCOS women: a pilot randomized study. J Ovarian Res. 2015;8(1):32.

22. Wouters EF, Bredenbröker D, Teichmann P, et al. Effect of the phosphodiesterase 4 inhibitor roflumilast on glucose metabolism in patients with treatment-naive, newly diagnosed type 2 diabetes mellitus. J Clin Endocrinol Metab. 2012;97(9):E1720-E1725.

23. Azevedo MF, Faucz FR, Bimpaki E, et al. Clinical and molecular genetics of the phosphodiesterases (PDEs). Endocr Rev. 2014;35(2):195-233.

24. Engels P, Fichtel K, Lübbert H. Expression and regulation of human and rat phosphodiesterase type IV isogenes. FEBS Lett. 1994;350(2-3):291-295.

25. Kenk M, Greene M, Thackeray J, et al. In vivo selective binding of (R)[11C]rolipram to phosphodiesterase-4 provides the basis for studying intracellular cAMP signaling in the myocardium and other peripheral tissues. Nucl Med Biol. 2007;34(1):71-77.

26. Nakamura J, Okamura N, Kawakami Y. Augmentation of lipolysis in adipocytes from fed rats, but not from starved rats, by inhibition of rolipram-sensitive phosphodiesterase 4. Arch Biochem Biophys. 2004;425(1):106-114.

27. Omar B, Banke E, Ekelund M, Frederiksen S, Degerman E. Alterations in cyclic nucleotide phosphodiesterase activities in omental and subcutaneous adipose tissues in human obesity. Nutr Diabetes. 2011;1(8):e13.

28. Enoksson S, Degerman E, Hagström-Toft E, Large V, Arner P. Various phosphodiesterase subtypes mediate the in vivo antilipolytic effect of insulin on adipose tissue and skeletal muscle in man. Diabetologia. 1998;41(5):560-568.

29. Waddleton D, Wu W, Feng Y, et al. Phosphodiesterase 3 and 4 comprise the major cAMP metabolizing enzymes responsible for insulin secretion in INS-1 (832/13) cells and rat islets. Biochem Pharmacol. 2008;76(7):884-893.

30. Friedlander RS, Moss CE, Mace J, et al. Role of phosphodiesterase and adenylate cyclase isozymes in murine colonic glucagon-like peptide 1 secreting cells. Br J Pharmacol. 2011;163(2):261-271.
31. Roflumilast medication information. https://www.accessdata.fda.gov/ drugsatfda_docs/label/2011/022522s0001bl.pdf. Accessed February 10, 2017.

32. First MB, Spitzer RL, Gibbon M, Williams JBW. Structured Clinical Interview for DSM-IV Axis 1 Disorders. Washington, DC, USA: American Psychiatric Press, Inc; 1996.

33. Possner K, Brown GK, Stanley B. The Columbia-suicide severity rating scale: internal validity and internal consistency findings from three multisite studies with adolescents and adults. Am J Psychiatry. 2011;168(12): 1266-1277.

34. Mifflin MD, St Jeor ST, Hill LA, Scott BJ, Daugherty SA, Koh YO. A new predictive equation for resting energy expenditure in healthy individuals. Am J Clin Nutr. 1990;51(2):241-247.

35. Institute of Medicine. Dietary Reference Intakes: The Essential Guide to Nutrient Requirements. Washington, DC: The National Academies Press; 2006.

36. Defronzo RA, Tobin JD, Andres R. Glucose clamp technique: a method for quantifying insulin secretion and resistance. Am J Physiol. 1979;237(3):E214-E223.

37. Muniyappa R, Noureldin R, Ouwerkerk R, et al. Myocardial fat accumulation is independent of measures of insulin sensitivity. J Clin Endocrinol Metab. 2015;100(8):3060-3068.

38. Ouwerkerk R, Pettigrew RI, Gharib AM. Liver metabolite concentrations measured with 1H MR spectroscopy. Radiology. 2012;265(2):| 565-575.

39. Magkos F, Fabbrini E, Korenblat K, Okunade AL, Patterson BW, Klein S. Reproducibility of glucose, fatty acid and VLDL kinetics and multiorgan insulin sensitivity in obese subjects with non-alcoholic fatty liver disease. Int J Obes. 2011;35(9):1233-1240.

40. Zornitzki T, Blaychfeld-Magnazi M, Knobler H, Ulman M. The effect of phlebotomy-induced hemolysis on insulin level determination. Endocr Pract. 2015;21(10):1093-1097.

41. White WB, Cooke GE, Kowey PR, et al. Cardiovascular safety in patients receiving roflumilast for the treatment of COPD. Chest. 2013;144(3):758-765.

42. Vollert S, Kaessner N, Heuser A, et al. The glucose-lowering effects of the PDE4 inhibitors roflumilast and roflumilast-N-oxide in $\mathrm{db} / \mathrm{db}$ mice. Diabetologia. 2012;55(10):2779-2788.

43. Ong WK, Gribble FM, Reimann F, et al. The role of the PDE4D cAMP phosphodiesterase in the regulation of glucagon-like peptide-1 release. Br J Pharmacol. 2009;157(4):633-644.

44. Meier JJ, Gethmann A, Götze O, et al. Glucagon-like peptide 1 abolishes the postprandial rise in triglyceride concentrations and lowers levels of non-esterified fatty acids in humans. Diabetologia. 2006;49(3):452-458.

45. Hermansen K, Bækdal TA, Düring M, et al. Liraglutide suppresses postprandial triglyceride and apolipoprotein B48 elevations after a fat-rich meal in patients with type 2 diabetes: a randomized, doubleblind, placebo-controlled, cross-over trial. Diabetes Obes Metab. 2013;15(11):1040-1048.

46. Bachmann OP, Dahl DB, Brechtel K, et al. Effects of intravenous and dietary lipid challenge on intramyocellular lipid content and the relation with insulin sensitivity in humans. Diabetes. 2001;50(11):2579-2584.

47. Lara-Castro C, Newcomer BR, Rowell J, et al. Effects of short-term very low-calorie diet on intramyocellular lipid and insulin sensitivity in nondiabetic and type 2 diabetic subjects. Metabolism. 2008;57(1):1-8.

48. Möllmann J, Kahles F, Lebherz C, et al. The PDE4 inhibitor roflumilast reduces weight gain by increasing energy expenditure and leads to improved glucose metabolism. Diabetes Obes Metab. 2017;19(4):496-508.

49. Chai W, Dong Z, Wang N, et al. Glucagon-like peptide 1 recruits microvasculature and increases glucose use in muscle via a nitric oxidedependent mechanism. Diabetes. 2012;61(4):888-896.

50. Ohnuki Y, Umeki D, Mototani Y, et al. Role of phosphodiesterase 4 expression in the Epac1 signaling-dependent skeletal muscle hypertrophic action of clenbuterol. Physiol Rep. 2016;4(10):e12791. 
51. Hodson DJ, Mitchell RK, Bellomo EA, et al. Lipotoxicity disrupts incretin-regulated human $\beta$ cell connectivity. J. Clin. Invest. 2013;123(10):4182-4194.

52. Pérez-Torres S, Miró X, Palacios JM, Cortés R, Puigdoménech P, Mengod G. Phosphodiesterase type 4 isozymes expression in human brain examined by in situ hybridization histochemistry and [3H]rolipram binding autoradiography. Comparison with monkey and rat brain. J Chem Neuroanat. 2000;20(3-4):349-374.

53. Lönnqvist F, Nyberg B, Wahrenberg H, Arner P. Catecholamineinduced lipolysis in adipose tissue of the elderly. J Clin Invest. 1990;85(5):1614-1621.

54. Camell CD, Sander J, Spadaro O, et al. Inflammasome-driven catecholamine catabolism in macrophages blunts lipolysis during ageing. Nature. 2017;27(7674):119-123.

55. Franceschi C, Garagnani P, Parini P, Giuliani C, Santoro A. Inflammaging: a new immune-metabolic viewpoint for age-related diseases. Nat Rev Endocrinol. 2018;14(10):576-590.

56. Brechtel K, Dahl DB, Machann J, et al. Fast elevation of the intramyocellular lipid content in the presence of circulating free fatty acids and hyperinsulinemia: a dynamic 1H-MRS study. Magn Reson Med. 2001;45(2):179-183.

57. Byrne MM, Gliem K, Wank U, et al. Glucagon-like peptide 1 improves the ability of the beta-cell to sense and respond to glucose in subjects with impaired glucose tolerance. Diabetes. 1998;47(8):1259-1265.
58. Santilli F, Simeone PG, Guagnano MT, et al. Effects of liraglutide on weight loss, fat distribution, and $\beta$-cell function in obese subjects with prediabetes or early type 2 diabetes. Diabetes Care. 2017;40(11):1556-1564.

59. Sanz MJ, Cortijo J, Taha MA, et al. Roflumilast inhibits leukocyteendothelial cell interactions, expression of adhesion molecules and microvascular permeability. Br J Pharmacol. 2007;152(4):481-492.

60. Chou HH, Hsu LA, Wu S, Teng MS, Sun YC, Ko YL. Leptin-to-Adiponectin ratio is related to low grade inflammation and insulin resistance independent of obesity in non-diabetic Taiwanese: a cross-sectional cohort study. Acta Cardiol Sin. 2014;30(3):204-214.

61. Frühbeck G, Catalán V, Rodríguez A, et al. Normalization of adiponectin concentrations by leptin replacement in ob/ob mice is accompanied by reductions in systemic oxidative stress and inflammation. Sci Rep. 2017;7(1):2752.

62. Barreiro E, Puig-Vilanova E, Salazar-Degracia A, Pascual-Guardia S, Casadevall C, Gea J. The phosphodiesterase-4 inhibitor roflumilast reverts proteolysis in skeletal muscle cells of patients with COPD cachexia. J Appl Physiol. 2018;125(2):287-303.

63. Ruscica M, Ferri N, Macchi C, Corsini A, Sirtori CR. Lipid lowering drugs and inflammatory changes: an impact on cardiovascular outcomes? Ann Med. 2018;32(1):1-24.

64. Burkewitz K, Zhang Y, Mair WB. AMPK at the nexus of energetics and aging. Cell Metab. 2014;20(1):10-25. 


\section{Supplementary material}

\section{Methods}

Assessment of muscle and hepatic insulin sensitivity and vascular function

Hepatic insulin sensitivity was assessed during fasting and during the clamp. For the fasting condition, a hepatic insulin resistance index was calculated as the product of hepatic glucose production and fasting plasma insulin concentration. A stable isotope technique with deuterium glucose as a tracer was used to determine basal endogenous glucose production. $\left[6,6-{ }^{2} \mathrm{H}_{2}\right]$ glucose was infused as an initial bolus of $5.1 \mathrm{mg} / \mathrm{kg}$, then followed by a constant rate of $0.072 \mathrm{mg} / \mathrm{kg} /$ minute for 3 hours. At the end of the 3 -hour time point, blood samples for $\left[6,6-{ }^{2} \mathrm{H}_{2}\right]$

Table SI Baseline characteristics of subjects who completed the study $(\mathrm{n}=8)$

\begin{tabular}{|l|l|}
\hline Mean age, years (SD) & $48.5(4.2)$ \\
\hline Distribution of Male/Female & $6 / 2$ \\
\hline $\begin{array}{l}\text { Race distribution, African or African-American/Caucasian/ } \\
\text { Hispanic }\end{array}$ & $5 / 2 / 1$ \\
\hline Average BMI, $\mathrm{kg} / \mathrm{m}^{2}(\mathrm{SD})$ & $31.2(3.3)$ \\
\hline Total number of subjects with prediabetes & 8 \\
\hline Total number of subjects with hypertension & 2 \\
\hline Number of subjects with hyperlipidemia & 2 \\
\hline $\begin{array}{l}\text { Number of subjects on no medications } \\
\text { Number of subjects on multivitamin only }\end{array}$ & 4 \\
\hline Number of subjects on antihypertensive medication & 2 \\
\hline Number of subjects on medication for dyslipidemia & 2 \\
\hline
\end{tabular}

Abbreviation: BMI, body mass index. glucose were collected every 10 minutes for 30 minutes for measurement by liquid chromatography-mass spectrometry. ${ }^{1}$

For the hyper-insulinemic euglycemic clamp, insulin was infused at a constant rate of $40 \mathrm{mU} / \mathrm{m}^{2} /$ minute following a loading dose of double the rate for the first 8 minutes. To access insulin induced suppression of hepatic gluconeogenesis during the clamp, $\left[6,6-{ }^{2} \mathrm{H}_{2}\right]$ glucose was infused at a rate of 0.0182 $\mathrm{mg} / \mathrm{kg} / \mathrm{minute}$. Serum glucose level was assessed every 5-10 minutes, and intravenous glucose infusion rate was adjusted to maintain the serum glucose level as close to $100 \mathrm{mg} / \mathrm{dl}$ as possible. Blood samples for assessing mitochondrial biogenesis of polymorphonuclear blood cells were obtained in the fasted state before the onset of the clamp and tracer procedures.

\section{Assessment of the incretin effect, circulating and inflammatory markers and adipocytokines}

Active GLP-1 and total GIP were measured in plasma containing DPP IV inhibitor using immunoassay kits from Meso Scale Discovery (MSD) (Rockville, MD). These kits are a sandwich immunoassay that uses electrochemiluminescence Sulfo-tag ${ }^{\mathrm{TM}}$ labels conjugated to detection antibodies that emit light upon electrochemical stimulation initiated at the electrode surfaces of microplates. The intra- and inter-assay CV were $4.03 \%$ and $5.62 \%$ for active GLP- 1 and $4.39 \%$ and $7.06 \%$ for total GIP, respectively.

Adiponectin, leptin, TNF- $\alpha$, E-selectin, MCP-1, VCAM1, and ICAM-1 were measured using the human magnetic beads Luminex screening assays from R\&D Systems (Minneapolis, MN, USA) according to the manufacturer's

Table S2 Profile of pertinent physical and laboratory parameters before and after roflumilast

\begin{tabular}{|l|l|l|l|}
\hline $\begin{array}{l}\text { Clinical category, } \\
\text { units of measurement }\end{array}$ & $\begin{array}{l}\text { Pre-roflumilast, } \\
\text { Mean (SE) }\end{array}$ & $\begin{array}{l}\text { Post-roflumilast, } \\
\text { Mean (SE) }\end{array}$ \\
\hline Common clinical examination parameters of interest & $97.98(4.8)$ & $96.26(5.2)$ & 0.12 \\
\hline Body weight, kg & $121(3.7)$ & $124(3.2)$ & 0.42 \\
\hline Systolic BP, mmHg & $71(3.0)$ & $72(3.3)$ & 0.92 \\
\hline Diastolic BP, mmHg & $66(3.7)$ & $71(4.1)$ & $0.14^{*}$ \\
\hline Pulse, bpm & $5.77(0.13)$ & $5.72(0.09)$ & 0.78 \\
\hline Common clinical laboratory parameters of interest & 0.50 \\
\hline Hemoglobin Alc, \% & $1.50(0.27)$ & $1.92(0.65)$ & 0.05 \\
\hline TSH, mclU/mL & $19.88(I .0)$ & $17.75(I .1)$ & $19.88(3.3)$ \\
\hline AST, U/L & $21.5(2.9)$ & & 0.38 \\
\hline ALT, U/L
\end{tabular}

Notes: $\mathrm{N}=8$ for all variables except for TSH $(n=7)$. $P$-value as determined using Related Samples-Wilcoxon Signed Rank Test. All other $p$-values are from paired $t$-test analysis.

Abbreviations: ALT, Alanine Aminotransferase; AST, Aspartate Aminotransferase; bpm, beats per minute; TSH, thyroid stimulating hormone. 
manual. ${ }^{2}$ The coefficient of variation was less than $10 \%$ for all the samples.

\section{Assessment of mitochondrial biogenesis}

Polymorphonuclear blood cells were isolated from whole blood, which was first centrifuged at room temperature at $1,800 \mathrm{x} g$ for 25 minutes. The cell suspension was harvested, washed twice with PBS, and then centrifuged for $10 \mathrm{~min}$ utes at $600 \mathrm{x}$ g. Cell pellets from the second centrifuging were then collected and stored in liquid nitrogen until the time for performing the mitochondrial biogenesis assess- ment. Mitochondrial biogenesis was assessed as previously described. ${ }^{3}$

\section{References}

1. Brown RJ, Valencia A, Startzell M, et al. Metreleptin improves insulin sensitivity independent of food intake in humans with lipodystrophy. $J$ Clin Invest. 2018;128(8):3504-3516.

2. Magnetic Luminex Assay. [Package insert]; Available from: https:// resources.rndsystems.com/pdfs/datasheets/lxsahm.pdf. Accessed March 29th, 2017.

3. Park SJ, Gavrilova O, Brown AL, et al. DNA-PK promotes the mitochondrial, metabolic, and physical decline that occurs during aging. Cell Metab. 2017;25(5):1135-1146.e7.
Diabetes, Metabolic Syndrome and Obesity: Targets and Therapy is an international, peer-reviewed open-access journal committed to the rapid publication of the latest laboratory and clinical findings in the fields of diabetes, metabolic syndrome and obesity research. Original research, review, case reports, hypothesis formation, expert

\section{Dovepress}

opinion and commentaries are all considered for publication. The manuscript management system is completely online and includes a very quick and fair peer-review system, which is all easy to use. Visit http://www.dovepress.com/testimonials.php to read real quotes from published authors.

Submit your manuscript here: https://www.dovepress.com/diabetes-metabolic-syndrome-and-obesity-targets-and-therapy-journal 